\title{
Acceptability of an Online Health Videogame to Improve Diet and Physical Activity in Elementary School Students: "Fitter Critters"
}

\author{
Kristin L. Schneider, PhD, John Ferrara, MA, ${ }^{2}$ Bri Lance, BA, ${ }^{2}$ Andrew Karetas, ${ }^{2}$ Susan Druker, MA, \\ Emily Panza, BA, Barbara Olendzki, RD, MPH, LDN, Victoria Andersen, MS, RD, LDN, and Lori Pbert, PhD
}

\begin{abstract}
Objective: Interest in health videogames to stimulate health behavior change is increasing, yet little research exists on their use. This study tested the acceptability of an online health videogame called "Fitter Critters ${ }^{\mathrm{TM}}$ " (Megazoid Games, Collegeville, PA) for improving healthy diet and activity in elementary school students. Subjects and Methods: In October and November 2011, fifth grade students $(n=97)$ from a school in central Massachusetts played the game for 1 week during their health class. Measures of nutrition and activity knowledge, attitudes, and self-efficacy were completed prior to playing the game and again on the final day along with a videogame acceptability questionnaire.

Results: The videogame was highly acceptable to participants as measured by the acceptability questionnaire mean rating of $4.52(\mathrm{SD}=0.60)$, where $1=$ strongly disagree and $5=$ strongly agree; $73 \%$ of students played the game at least once outside of class. Significant increases in positive attitudes toward healthy eating $(P<0.001)$ and healthy eating self-efficacy $(P=0.02)$ and marginally significant increases in nutrition knowledge $(P=0.08)$ were observed.

Conclusions: The "Fitter Critters" health videogame engages students in learning about healthy eating and activity. Further research should assess whether the positive changes observed in knowledge, attitudes, and selfefficacy translate into behavior change.
\end{abstract}

\section{Introduction}

C HILDHOOD OBESITY IS A SIGNIFICANT problem, with 32\% overweight or obese in the United States. ${ }^{1}$ Prevention is key to combating obesity and necessitates unique strategies that engage children and can be implemented widely. One novel approach uses health videogames to encourage healthy eating and activity. Although once considered exclusively for entertainment, videogames are increasingly being used as a captivating way to educate children on issues such as diabetes $^{2}$ and healthy eating. ${ }^{3,4}$ Two reviews reported that health videogames improved diet and physical activity in children. ${ }^{5,6}$ This promising initial work led Read and Shortell ${ }^{7}$ to advocate for research on whether health videogames facilitate behavior change.

Access is critical for enabling health videogames to prevent obesity in children. Schools may be an ideal setting for improving access to these games because $95 \%$ of children attend school. ${ }^{8}$ The integration of health videogames into schools to improve weight-related behaviors is largely unexplored but has great potential for preventing childhood obesity. Videogames have been used in schools to teach educational content and convey health messages related to nutrition, ${ }^{9}$ alcohol and drug use, ${ }^{10-12}$ and hygiene. ${ }^{13}$ Videogame acceptability may be critical to the ability of these games to impact behavior, as student satisfaction and usability ratings of videogames were positively correlated with knowledge gained. ${ }^{10,11}$

"Fitter Critters"T," developed by Megazoid Games (Collegeville, PA), is an online videogame intended for use in schools for children 8-12 years old, which won 2nd place in the U.S. Department of Agriculture (USDA)/Michelle Obama 2010 Apps for Healthy Kids contest. In the game, the player is responsible for the health of a virtual pet (Critter). The game aims to increase healthy eating and activity knowledge and improve health behaviors by having children complete quests to learn how food and activity choices influence their Critter's behavior and health. By choosing healthy foods without surpassing the fat, sugar, and caloric allotment, the Critter

\footnotetext{
${ }^{1}$ University of Massachusetts Medical School, Worcester, Massachusetts.
}

${ }^{2}$ Megazoid Games, Collegeville, Pennsylvania. 
becomes healthier, wins more sport games, earns more money, and is sick less. Having the Critter be physically active improves its health and reduces its body fat. Critters who frequently exceed the fat, sugar, or calorie limits become unhealthy, earn less money, are more likely to be sick, and perform poorly in sport games. These Critters reject healthy choices, such that poor choices reinforce one another; this can only be reversed via consistent healthy choices.

This study assessed the acceptability of the "Fitter Critter" videogame by fifth grade students. We hypothesized that students would find the game highly acceptable as evidenced by (1) positive scores on a videogame acceptability questionnaire that measured satisfaction, usability, and relevance to their eating and activity behavior, (2) playing the game outside of school, and (3) positive teacher ratings. We also hypothesized that playing the game would increase nutrition and activity knowledge, positive nutrition attitudes, and selfefficacy for healthy eating and activity.

\section{Subjects and Methods}

\section{Participants}

Participants were fifth grade students from an elementary school in central Massachusetts $(n=97)$. The school enrolls 782 students, $49 \%$ of which are female, $91 \%$ are Caucasian, and $28.5 \%$ come from low-income families.

\section{Procedures}

One week prior to their regularly scheduled health class, students received a handout on the study to give to their parents, so that parents could contact the health teacher with questions. The following week, children attended their 52minute health class in the computer lab, so each student had their own computer. At the first class, children were given the option to complete questionnaires, which was not mandatory for game playing. Participants who provided assent clicked on an online survey link where they completed baseline questionnaires, which took 15 minutes. The survey was hosted by REDCap, a secure Web-based program designed to collect clinical research data. [REDCap (Research Electronic Data Capture $)^{14}$ is an application designed to support data capture for research studies, providing (1) an intuitive interface for validated data entry, (2) audit trails for tracking data manipulation and export procedures, (3) automated export procedures for seamless data downloads to common statistical packages, and (4) procedures for importing data from external sources.] Children then logged into the game and played the game during health class for five consecutive days (one cohort of students only had the opportunity to play the game for 4 days because the school closed 1 day because of bad weather). Other than the first and the last day, when they completed questionnaires, participants spent the entire 52 minutes of class time playing the game. Each day, they were instructed by their teacher to complete a list of quests (described below). Students who did not complete the previous day's quests had to complete them before moving on. To encourage collaboration and knowledge sharing, students could assist one another with the game. The teacher mainly served to troubleshoot problems students had with the game (e.g., could not log-on) and did not provide explicit instructions on how to complete quests. On Day 5, assenting par- ticipants completed the postgame questionnaire using REDCap. Four student cohorts participated in October and November 2011.

Because "Fitter Critters" is an online game, participants could play it outside of class. Students received a handout after the first class with instructions on accessing the game but received no further encouragement to play. Procedures were approved by the University of Massachusetts Medical School's Institutional Review Board.

\section{"Fitter Critters"}

The game incorporates aspects of health videogames that are theorized to be important to game immersion, practical knowledge of behavior, behavior change skill development, and behavior self-control skill development, with the goal of facilitating behavior change. ${ }^{15}$ Game features are described below, and Table 1 indicates which theorized aspects critical to behavior change are covered by each game feature:

1. Quests. The game had 17 quests to enhance motivation for game playing, help master the game basics (e.g., visit the grocer, purchase foods), and increase nutrition and activity knowledge (e.g., fill healthy bars without filling unhealthy bars).

2. Meters. The game displays meters representing the Critter's health and diet. The health meter changes based on the Critter's diet and physical activity. The diet meters represent daily nutritional requirements, based on the USDA recommendations for children 8-12 years old, and fill as the player feeds the Critter. Meters reset daily so they can be filled again the next time the player logs on. Figure 1 shows a screenshot.

3. Food. To feed the Critter, food may be purchased at a grocer or restaurant or harvested for free from the garden. Players can access nutritional information, which comes from the USDA Food and Nutrient Database for Dietary Studies 3.L dataset.

4. Cooking. Players can create recipes, which they can cook for the Critter. Players can feed their Critter the meal or sell it to the restaurant for profit. Unhealthy meals cannot be sold for more than the cost of ingredients.

5. Sport games. Critters can compete in the shot put or foot race. Although players can manually help their Critter perform better, success is linked to the Critter's health meter. The Critter earns $\$ 50$ every time it wins, but competing burns calories and improves health regardless of outcome. Figure 2 shows a screenshot.

6. Work. When the Critter is healthy it goes to work and earns money. As its health improves, it earns more money.

7. Sick days. The Critter's health meter determines whether it becomes sick. When the Critter is sick, it cannot work or play sport games.

8. Decorations. Players can use the Critter's money to decorate their Critter's home.

\section{Measures}

To ensure confidentiality and minimize the likelihood of student concerns about their parent or teacher learning their responses, participants did not report demographic information. 
Table 1. Game Features and the Aspects of Behavior Change They Address

\begin{tabular}{lcccc}
\hline & \multicolumn{3}{c}{ Theorized aspects critical to behavior change } \\
\cline { 2 - 5 } & Immersion & $\begin{array}{c}\text { Knowledge } \\
\text { of behavior }\end{array}$ & $\begin{array}{c}\text { Behavior change } \\
\text { skill development }\end{array}$ & $\begin{array}{c}\text { Behavior self-control } \\
\text { skill development }\end{array}$ \\
\hline Quests & $\mathrm{X}$ & $\mathrm{X}$ & $\mathrm{X}$ & $\mathrm{X}$ \\
Meters & & $\mathrm{X}$ & $\mathrm{X}$ & $\mathrm{X}$ \\
Food & $\mathrm{X}$ & $\mathrm{X}$ & $\mathrm{X}$ \\
Cooking & $\mathrm{X}$ & & $\mathrm{X}$ \\
Sport games & $\mathrm{X}$ & & \\
Work & $\mathrm{X}$ & & \\
Sick days & $\mathrm{X}$ & & \\
Home decorations & & & \\
\hline
\end{tabular}

Knowledge. Participants completed the 14-item nutrition knowledge questionnaire used in the Child and Adolescent Trial for Cardiovascular Health (CATCH) study, which is a valid and reliable measure of nutrition knowledge in children. ${ }^{16}$ Responses were coded as correct or incorrect using the CATCH scoring criteria. ${ }^{16,17}$ Total number correct was summed for nutrition knowledge. Participants completed two multiple-choice questions where they selected the recommended daily amount of physical and sedentary activity for children. These two questions were coded as correct or incorrect based on the national activity recommendations for children. $^{17}$

Self-efficacy. Participants completed the reliable and valid measure of self-efficacy for healthy eating developed for CATCH. ${ }^{18}$ Participants completed the eight-item Physical Activity Self-efficacy Scale, which has demonstrated excellent reliability and validity in children. ${ }^{19,20}$ Total scores for each of these scales were created by summing all items so that higher scores indicated greater self-efficacy.

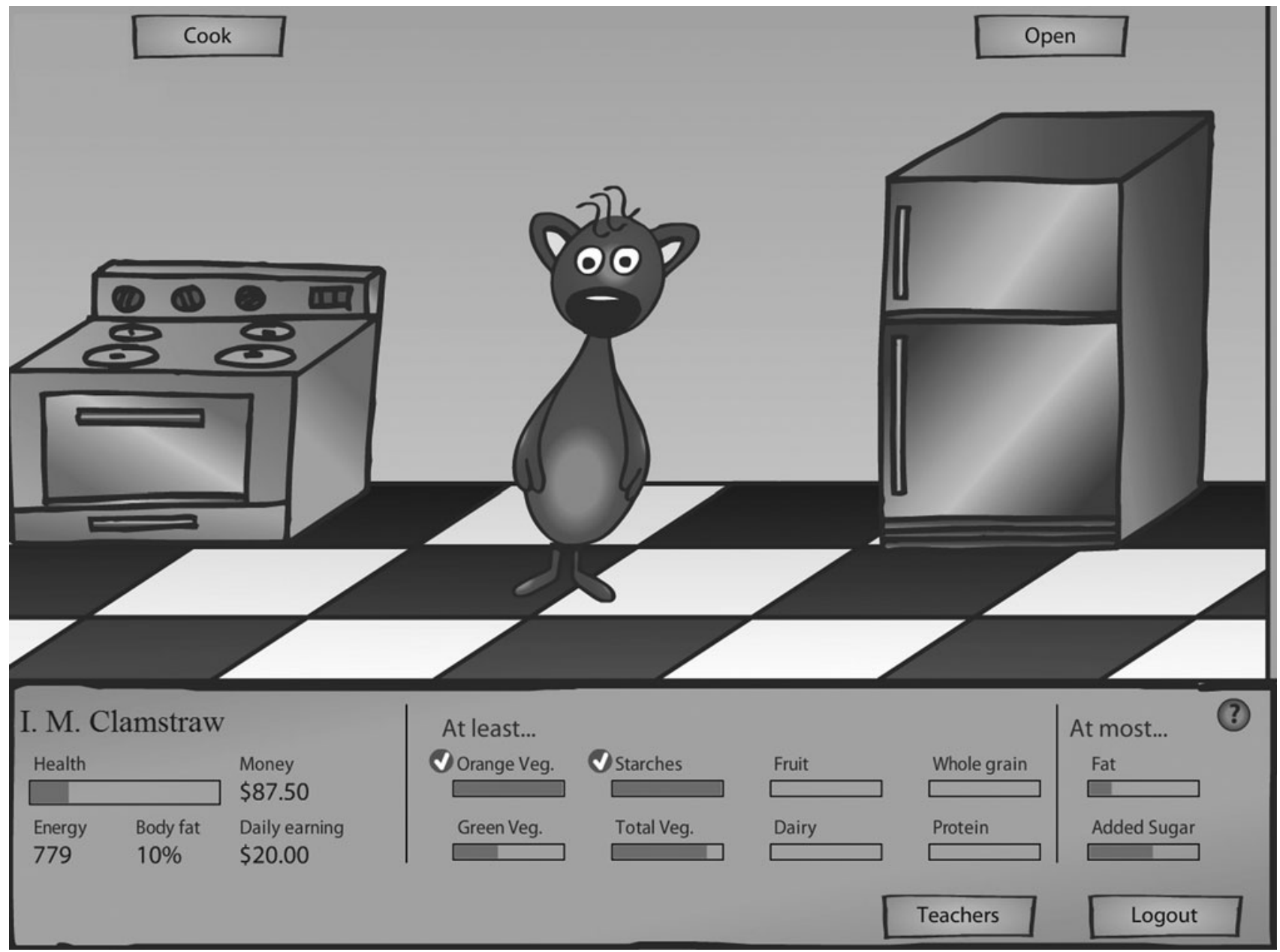

FIG. 1. Screen shot of the "Fitter Critters" videogame: the Critter in its kitchen with meters. 


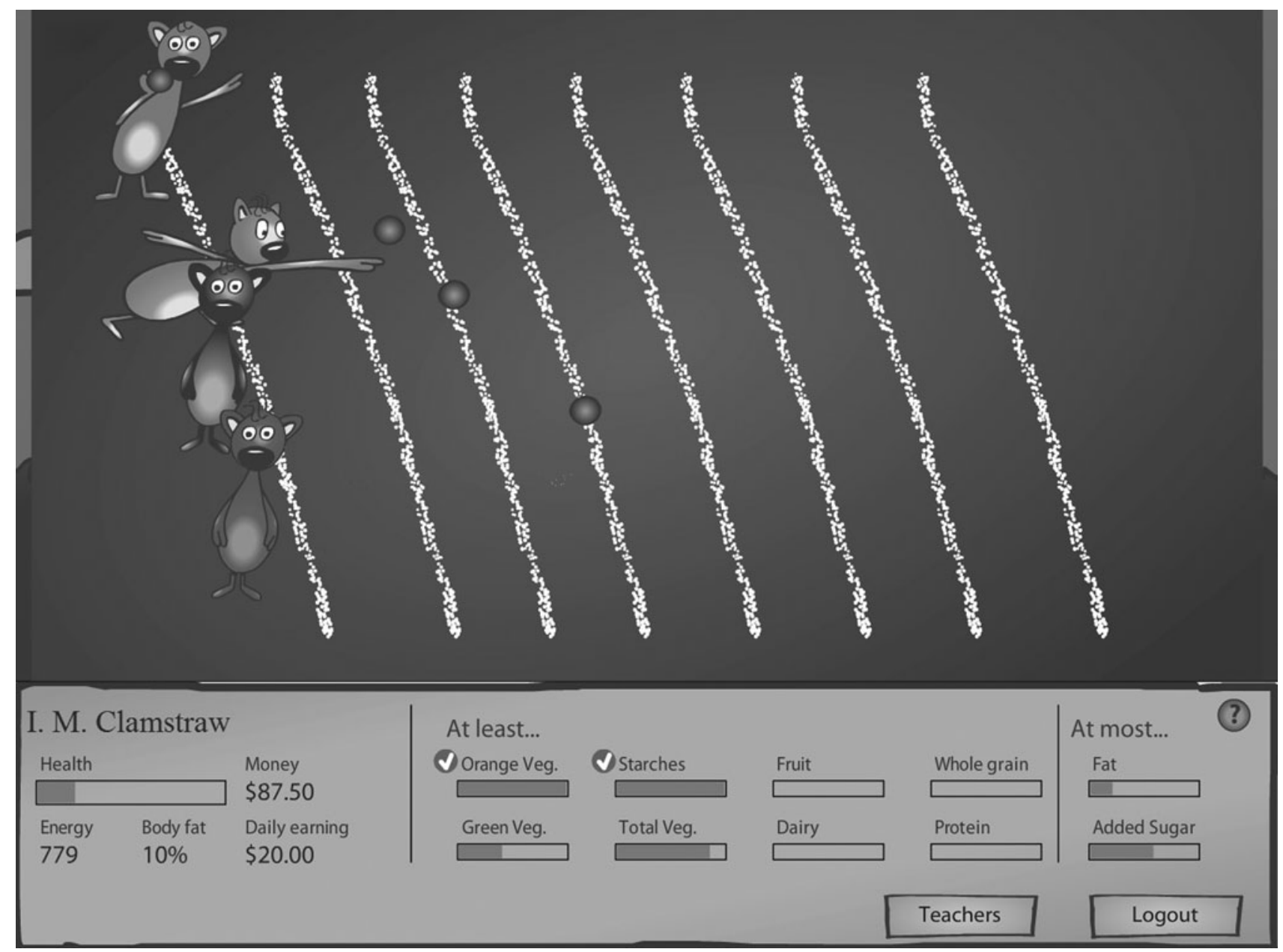

FIG. 2. Screen shot of the "Fitter Critters" videogame: the Critter competing in the shot put game.

Attitudes. Participants completed the 14-item reliable and valid measure of healthy eating attitudes developed for CATCH. ${ }^{16}$ They rated each item on a $1-5$ scale, where $1=$ strongly agree and $5=$ strongly disagree. Items were reverse-scored and then summed so that higher scores indicated more healthy eating attitudes.

Videogame acceptability. Because we were interested in capturing the acceptability of specific components of the "Fitter Critter" game, we created our own survey. The Principal Investigator began by amending items used by Lazareck et al. $^{21}$ in their evaluation of a videogame that teaches hygiene (e.g., I would recommend this game to friends; I would play this game at home). She then added items that were specific to the game (e.g., I liked decorating my Critter's home; Playing "Fitter Critters" helped me learn about why it is important to be physically active). All items were reviewed by the study team for content and readability. The questionnaire contained 19 items rated on a 1-5 scale, where $1=$ strongly disagree and $5=$ strongly agree. Acceptability was assessed by examining the mean rating for each of the 19 items and the mean of all items. Cronbach's $\alpha$ for the total scale equaled 0.94 .

Two additional open-ended questions asked participants to describe what they liked most and least about the game. Responses to open-ended questions were coded by the Prin- cipal Investigator. Coding entailed first reviewing all of the responses to identify common themes for creating codes. After the Principal Investigator created a list of codes, she assigned each response a code (17 participants mentioned more than one code in a response, in which case each part of the response received a different code). Another author (E.P.) then reviewed the codes and noted two discrepancies. The discrepancies were discussed, and consensus was achieved.

Videogame tracking. The game tracked game features at every log-on. Features tracked included the number of quests completed, sport games played, and log-ons. The total number of quests was documented during the student's last log-on. The number of sport games played was summed across the number of times the student played the game. The number of log-ons was calculated by summing the number of separate log-ons for each student. The Critter's health score and its percentage saturated fat intake were recorded each time students logged-on. The health score was measured on a 5-point scale, with 5 indicating the healthiest rating. At the start of the game the Critter has a health score of 2 and a percentage saturated fat intake of $20 \%$. The health score and percentage saturated fat intake were taken from the student's last log-on to examine the health of the Critter after the students played the game. 
Teacher ratings. At the end of each week, the teacher provided her assessment of overall student interest in the game on a $1-10$ scale, where $1=$ extremely bored and $10=$ extremely interested, and the frequency with which she heard students make different comments about the game (e.g., "I am bored") on a 5 -point scale, where $0=$ never and $4=$ always.

\section{Statistical analyses}

For participants with complete data, paired-samples $t$ tests were used to examine changes in nutrition knowledge, selfefficacy, and attitudes; $\chi^{2}$ tests were conducted for physical and sedentary activity knowledge. Descriptive and frequency analyses evaluated videogame acceptability and use.

\section{Results}

Of the 97 students who played the game, 75 (77\%) completed pre- and postgame questionnaires. One participant did not complete any questionnaires. Eighteen only completed the pregame questionnaire. Three participants only completed the postgame questionnaire.

Participants reported significant increases in diet selfefficacy $(t=-2.68, P=0.009)$ and positive attitudes toward healthy foods $(t=-5.29, P<0.001)$ and marginally significant increases in nutrition knowledge $(t=-1.75, P=0.08)$ (Table 2). Physical $\left[\chi^{2}(1)=29.73, P<0.001\right]$ and sedentary activity $\left[\chi^{2}(1)=16.34, P<0.001\right]$ knowledge significantly changed such that more participants chose incorrect answers after playing the game. In examining the raw data, $15 \%$ of participants who answered correctly on the pregame questionnaire chose a greater amount of physical activity on the postgame questionnaire, and another $15 \%$ chose a lower amount or no recommendation. For sedentary activity, $16 \%$ of participants who answered correctly on the pregame questionnaire selected 3 hours as the recommended amount or selected no recommendation on the postgame questionnaire. Physical activity self-efficacy did not change $(P=0.72)$.

The mean rating for the acceptability questionnaire was $4.52(\mathrm{SD}=0.60)$ on a scale where $1=$ strongly disagree and $5=$ strongly agree $(n=78)$. The lowest rated item was "I liked what the Critter looked like" (mean $=4.04, \mathrm{SD}=1.28$ ), and the highest rated items were "I liked playing the shot put game" (mean $=4.79, \mathrm{SD}=0.52)$ and "I want my Critter to be healthy"

Table 2. Pre- and Postgame Data on the Main Study Variables $(N=75)$

\begin{tabular}{|c|c|c|c|}
\hline \multirow[b]{3}{*}{ Diet self-efficacy } & Pregame & Postgame & \multirow[b]{2}{*}{$\mathrm{P}$} \\
\hline & \multicolumn{2}{|c|}{ Mean (SD) } & \\
\hline & $36.85(6.51)$ & $38.50(7.64)$ & 0.009 \\
\hline Diet attitudes & $59.14(6.08)$ & $62.22(7.74)$ & $<0.001$ \\
\hline Diet knowledge & 10.71 (1.97) & 11.04 (1.91) & 0.08 \\
\hline $\begin{array}{l}\text { Physical activity } \\
\text { self-efficacy }\end{array}$ & $22.34(1.94)$ & $22.44(2.33)$ & 0.72 \\
\hline \multicolumn{4}{|c|}{ Correct responses $(\%)$} \\
\hline $\begin{array}{l}\text { Physical activity } \\
\text { knowledge }\end{array}$ & $40(55.6)$ & $30(41.7)$ & $<0.001$ \\
\hline $\begin{array}{l}\text { Sedentary activity } \\
\text { knowledge }\end{array}$ & $36(50.0)$ & $34(47.2)$ & $<0.001$ \\
\hline
\end{tabular}

(mean $=4.78, \mathrm{SD}=0.66$ ) (Table 3). Of the open-ended questions, $43 \%$ of responses were categorized as liking the sport games best (Table 4). Although $5 \%$ of responses identified the quests as the best feature, 19\% of responses identified the quests as their least favorite feature (Table 5).

For all 97 students, the average number of log-ins was $11.96(\mathrm{SD}=5.88)$, with $73 \%$ logging on at least once outside of class. Students completed an average of $14.71(\mathrm{SD}=3.30)$ quests and played an average of $86.41(\mathrm{SD}=114.06)$ sport games. Average health scores and percentage saturated fat intake for their final log-ons were $3.54(\mathrm{SD}=1.64)$ and 15.63 $(\mathrm{SD}=7.63)$, respectively.

The average teacher overall game rating was 8.50 $(S D=0.58)$. Average ratings for the frequency of student statements about the game were low for "This is boring" (mean $=0.50, \mathrm{SD}=0.58$ ) and high for "This is fun" (mean $=3.00$, $\mathrm{SD}=0.0)$ and "I want to play more" (mean $=2.75, \mathrm{SD}=0.50)$.

\section{Discussion}

This study demonstrated that a health videogame designed to increase healthy eating and activity was feasible to

Table 3. Videogame Acceptability QuestionNAIRE ITEMs $(N=78)$

\begin{tabular}{|c|c|c|}
\hline Item & Mean & $S D$ \\
\hline I liked playing the shot put game. & 4.79 & 0.52 \\
\hline I want my Critter to be healthy. & 4.78 & 0.66 \\
\hline $\begin{array}{l}\text { It was easy to figure out how to play } \\
\text { the game. }\end{array}$ & 4.76 & 0.72 \\
\hline $\begin{array}{l}\text { I liked decorating my Critter's } \\
\text { home. }\end{array}$ & 4.68 & 0.65 \\
\hline $\begin{array}{l}\text { I would like to learn more things in } \\
\text { school by playing games like } \\
\text { "Fitter Critters." }\end{array}$ & 4.64 & 0.68 \\
\hline $\begin{array}{l}\text { I understood what was making the } \\
\text { Critter's health go up or down. }\end{array}$ & 4.56 & 0.89 \\
\hline $\begin{array}{l}\text { I would like to play this videogame } \\
\text { in computer class again. }\end{array}$ & 4.53 & 1.03 \\
\hline I liked feeding my Critter. & 4.52 & 0.82 \\
\hline I would play this game at home. & 4.51 & 0.95 \\
\hline I liked playing the race game. & 4.51 & 0.91 \\
\hline $\begin{array}{l}\text { Playing "Fitter Critters" helped me } \\
\text { learn about why it is important to } \\
\text { be physically active. }\end{array}$ & 4.50 & 0.85 \\
\hline I liked the Critter. & 4.48 & 0.88 \\
\hline $\begin{array}{l}\text { After playing the game I'm more } \\
\text { interested in eating fruits and } \\
\text { vegetables. }\end{array}$ & 4.47 & 0.95 \\
\hline $\begin{array}{l}\text { I know more about the foods I eat } \\
\text { than I did before I played the } \\
\text { game. }\end{array}$ & 4.43 & 0.86 \\
\hline $\begin{array}{l}\text { Playing "Fitter Critters" helped me } \\
\text { learn about how to eat healthy. }\end{array}$ & 4.41 & 0.86 \\
\hline $\begin{array}{l}\text { I would recommend this game to } \\
\text { friends. }\end{array}$ & 4.39 & 0.86 \\
\hline $\begin{array}{l}\text { I liked combining ingredients into } \\
\text { cooked meals for my critter. }\end{array}$ & 4.39 & 0.98 \\
\hline $\begin{array}{l}\text { I liked sharing the meals I cooked } \\
\text { with other players. }\end{array}$ & 4.38 & 0.89 \\
\hline I liked what the Critter looked like. & 4.04 & 1.28 \\
\hline
\end{tabular}

Items were rated on a 5 -point scale, where $1=$ strongly agree to $5=$ strongly disagree. 
Table 4. Participant-Coded Responses to “What Did You Like Most About the Game?" $(N=78)$

\begin{tabular}{lcc}
\hline & Frequency $^{\mathrm{a}}$ & $\%$ \\
\hline Games (shot put/foot race) & 38 & 43.18 \\
$\begin{array}{l}\text { Buying food/cooking/ } \\
\quad \text { feeding the Critter }\end{array}$ & 14 & 15.91 \\
Health-related/learned & 11 & 12.50 \\
$\quad$ something & 7 & \\
Decorating the Critter's home & 6 & 6.95 \\
Earning money & 4 & 4.85 \\
Quests & 3 & 3.41 \\
Everything & 2 & 2.27 \\
Certain game features (having & & \\
$\quad$ choice, having own Critter) & 1 & 1.14 \\
Critter & 1 & 1.14 \\
Nothing & 1 & 1.14 \\
I don't know & & \\
\hline
\end{tabular}

${ }^{\text {a }}$ The frequency sums to more than 78 because some participants mentioned more than one thing that they liked about the game.

use in health class and was highly acceptable and resulted in increased nutrition knowledge, positive attitudes toward healthy eating, and healthy eating self-efficacy. Playing the game had no impact on physical activity self-efficacy and decreased physical and sedentary activity knowledge.

The high acceptability ratings for the game are encouraging for further research on the ability of "Fitter Critters" to improve healthy eating and activity. Studies of health videogames used in school to increase health knowledge reported satisfaction and usability ratings ranging from 3.39 to 3.75 on a 5 -point scale, ${ }^{10,11}$ which is lower than the mean ratings observed in the present study. As satisfaction and usability appear to be correlated with knowledge gained, the high acceptability of "Fitter Critters" has implications for its ability to impact health knowledge and ultimately behavior.

Barriers to using videogames in classrooms for teaching include inflexible curriculum and lack of supporting materials. ${ }^{22}$ A barrier to use of health videogames may be teacher reluctance to sacrifice core academic lessons for nutrition and activity knowledge, given pressure to cover educational standards. The creators of "Fitter Critters" addressed these barriers by creating a companion curriculum that covers

Table 5. Participant-Coded Responses to "What Did You Like Least About the Game?" $(N=78)$

\begin{tabular}{lcc}
\hline & Frequency & $\%$ \\
\hline Quests & 15 & 19.23 \\
Miscellaneous game features & 15 & 19.23 \\
$\quad$ (e.g, walking back and forth) & & \\
Games & 10 & 12.82 \\
Being unhealthy & 10 & 12.82 \\
Critter & 6 & 7.69 \\
Glitches & 6 & 7.69 \\
Money-related & 5 & 6.41 \\
Nothing & 5 & 6.41 \\
Buying food/cooking/feeding & 2 & 2.56 \\
$\quad$ the Critter & 1 & \\
Decorating the Critter's home & 1 & 1.28 \\
Everything & 2 & 2.56 \\
I don't know/unclear & & \\
\hline
\end{tabular}

health behavior content from the game and meets some of the national education standards for health, mathematics, education technology, English language arts, and arts education. They also developed school environment components to reinforce healthy eating and activity, including (1) sticker codes children receive when they purchase/consume healthy foods or engage in physical activity at school, which are entered into the game to improve the Critter's health, and (2) changes to the school environment that reinforce the game and its health behavior content (e.g., display boards). The complementary components are a strength of this approach, enhancing the likelihood of teachers supporting "Fitter Critters" implementation.

Although schools provide an opportunity to educate students on health behaviors, the home has a strong impact on healthy eating and activity. ${ }^{23}$ One student commented, "The thing I liked most about the game is how you . . . get to actually cook your food. I may not know how to cook in real life, but it's fun cooking in here." The students' interest in cooking, recipes, and feeding the Critter suggests that there may be an opportunity to extend the game into the home by involving children in preparing healthy meals. In this study, parents offered tacit support of the game because no parents kept their children from playing the game in school. Conducting research with parents on how the game could support healthy eating and activity would be key to integrating "Fitter Critters" into the home. The accessibility of "Fitter Critters" in any setting with a computer and Internet connection is a strength of this approach to improving healthy eating and activity in children.

Schools and parents may be hesitant to use a sedentary activity, like a health videogame, to encourage healthy behaviors. Several game features address this concern. First, the game was designed for classroom use, times children are typically sedentary. Second, the game was not designed to be played for long periods of time in one sitting. Although many videogames require extensive game playing to improve performance, knowledge, not playing time, is essential to improved performance in "Fitter Critters." Last, the game's message that physical activity increases the Critter's health is at odds with copious sedentary activity. Future studies should track physical activity levels to see if it declines, especially because most participants played the game at home at least once.

The lack of improvements in activity knowledge and selfefficacy may have occurred for a few reasons. The game is primarily focused on feeding the Critter rather than increasing the Critter's activity, as there is no meter assessing the Critter's activity and only three quests are physical activity related. Participating in physical activity increases the Critter's health and ability to win the sport games, but these changes may be too subtle for children to notice in 1 week. Also, the game does not explicitly or implicitly provide education on the recommended amounts of physical and sedentary activity. The game could be altered to emphasize activity more by adding activity-related meters and quests. For example, having the Critter sit on the couch for a long time could worsen the Critter's health. The game could also enable the Critter to purchase home exercise equipment, which could be used to improve its health.

Strengths of the study are the use of child and teacher ratings of acceptability and the objective use data captured by 
the game. Limitations include the lack of a control group, the lack of a longer-term follow-up measure, the short time frame for game exposure, and that $23 \%$ of participants did not complete pre- and postgame measures. A control group and follow-up measures would have been superfluous additions to examine the game's acceptability. The game was intended to be used with the eight-session companion school curriculum described earlier in the discussion, over the course of several weeks. Now that the game has demonstrated acceptability, the next step is to examine whether "Fitter Critters," in tandem with the curriculum and environmental components, can facilitate healthy eating and activity improvements.

In conclusion, a health videogame, "Fitter Critters," is acceptable to students and can be used in a classroom to increase nutrition knowledge, positive attitudes toward healthy eating, and healthy eating self-efficacy. Although more research is required to demonstrate the utility of "Fitter Critters" in promoting behavior change, this study represents an important first step toward the potential use of "Fitter Critters" in schools for obesity prevention.

\section{Acknowledgments}

We would like to thank Moira Larson for allowing us to use the "Fitter Critter" game in her classroom, as well as the students who participated in the study. Study data were collected and managed using REDCap electronic data capture tools hosted at the University of Massachusetts Medical School.

\section{Author Disclosure Statement}

K.L.S., L.P., S.D., E.P., B.O., and V.A. have no competing financial interests. J.F., B.L., and A.K. founded the company Megazoid Games, which created the game "Fitter Critters."

\section{References}

1. Ogden C, Carroll M, Curtin L, et al. Prevalence of high body mass index in US children and adolescents. JAMA 2010; 303:242-249.

2. DeShazo J, Harris L, Pratt W. Effective intervention or child's play? A review of video games for diabetes education. Diabetes Technol Ther 2010; 12:815-822.

3. Baranowski T, Baranowski J, Thompson D, et al. Video game play, child diet, and physical activity behavior change. Am J Prev Med 2011; 40:33-38.

4. Baranowski T, Baranowski J, Cullen KW, et al. Squire's Quest! Dietary outcome evaluation of a multimedia game. Am J Prev Med 2003; 24:52-61.

5. Baranowski T, Buday R, Thompson D, Baranowski J. Playing for real: Video games and stories for health-related behavior change. Am J Prev Med 2008; 34:74-82.

6. Guy S, Ratzki-Leewing A, Gwadry-Sridhar F. Moving beyond the stigma: Systematic review of video games and their potential to combat obesity. Int J Hypertens 2011; 2011: 179124.

7. Read JL, Shortell SM. Interactive games to promote behavior change in prevention and treatment. JAMA 2011; 305:17041705.

8. U.S. Bureau of the Census. Historical Statistics of the United States, Colonial Times to 1970. Washington, DC: Bureau of the Census, U.S. Department of Commerce, 1975.
9. Baranowski T, Cullen KW, Nicklas T, et al. Are current health behavioral change models helpful in guiding prevention of weight gain efforts? Obes Res 2003; 11(Suppl):23S-43S.

10. Klisch Y, Miller L, Wang S, Epstein J. The impact of a science education game on students' learning and perception of inhalants as body pollutants. J Sci Educ Technol 2012; 21:295-303.

11. Klisch Y, Miller LM, Beier ME, Wang S. Teaching the biological consequences of alcohol abuse through an online game: Impacts among secondary students. CBE Life Sci Educ 2012; 11:94-102.

12. Miller L, Schweingruber $H$, Oliver $R$, et al. Teaching neuroscience through Web adventures: Adolescents reconstruct the history and science of opioids. Neuroscientist 2002; 8:16-21.

13. Farrell D, Kostkova P, Weinberg J, et al. Computer games to teach hygiene: An evaluation of the e-Bug junior game. J Antimicrob Chemother 2011; 66:39-44.

14. Harris PA, Taylor R, Thielke R, et al. Research electronic data capture (REDCap) - A metadata-driven methodology and workflow process for providing translational research informatics support. J Biomed Inform 2009; 42:377-381.

15. Baranowski T, Baranowski J, Thompson D, Buday R. Behavioral science in video games for children's diet and physical activity change: Key research needs. J Diabetes Sci Technol 2011; 5:229-233.

16. Wilson AM, Margarey AM, Mastersson N. Reliability and relative validity of a child nutrition questionnaire to simultaneously assess dietary patterns associated with positive energy balance and food behaviours, attitudes, knowledge and environments associated with healthy eating. Int J Behav Nutr Phys Act 2008; 5:5.

17. Barlow SE. Expert committee recommendations regarding the prevention, assessment, and treatment of child and adolescent overweight and obesity: Summary report. Pediatrics 2007; 120(Suppl 4):S164-S192.

18. Parcel GS, Edmundson E, Perry CL, et al. Measurement of self-efficacy for diet-related behaviors among elementary school children. J Sch Health 1995; 65:23-27.

19. Bartholomew JB, Loukas A, Jowers EM, Allua S. Validation of the physical activity self-efficacy scale: Testing measurement invariance between Hispanic and Caucasian children. J Phys Act Health 2006; 3:70-78.

20. Motl RW, Dishman RK, Trost SG. Factorial validity and invariance of questionnaires measuring social-cognitive determinants of physical activity among adolescent girls. Prev Med 2000; 31:584-594.

21. Lazareck LJ, Farrell D, Kostkova P, et al. Learning by gaming-evaluation of an online game for children. Conf Proc IEEE Eng Med Biol Soc 2010; 2010:2951-2954.

22. Baek Y. What hinders teachers in using computer and video games in the classroom? Exploring factors inhibiting the uptake of computer and video games. Cyberpsychol Behav 2008; 11:665-671.

23. Rosenkranz RR, Dzewaltowski DA. Model of the home food environment pertaining to childhood obesity. Nutr Rev 2008; 66:123-140.

Address correspondence to: Kristin L. Schneider, PhD University of Massachusetts Medical School 55 Lake Avenue North Worcester, MA 01655

E-mail: Kristin.Schneider@umassmed.edu 